\title{
Rapid Assessment of Damage Potential of Earthquakes in Taiwan from the Beginning of $P$ Waves
}

\author{
by Yih-Min Wu and Hiroo Kanamori
}

\begin{abstract}
To rapidly assess the potential for damage of an earthquake for purposes of earthquake early warning in Taiwan, we used the peak displacement and velocity amplitudes of the first $3 \mathrm{sec}$ of the $P$ wave. The vertical-component records, highpass filtered at $0.075 \mathrm{~Hz}$, are used. We found that the peak initial-displacement amplitude (Pd) correlates well with the peak ground-motion displacement (PGD) and the peak ground-motion velocity (PGV) at the same site. When $\mathrm{Pd}>0.5 \mathrm{~cm}$, the event is most likely damaging. If $\mathrm{Pd}$ is combined with the period parameter $\tau_{c}$, determined in an earlier study, then $\tau_{c} \times \mathrm{Pd}$ provides an even more robust parameter for assessing the potential for damage.
\end{abstract}

\section{Introduction}

For timely seismic emergency response, rapid and accurate determination of the potential for damage of an earthquake is an important issue, especially in the operation of a seismic early-warning system (Nakamura, 1988; Kanamori et al., 1997; Teng et al., 1997; Wu and Teng, 2002; Allen and Kanamori, 2003; Wu and Kanamori, 2005). The potential for damage depends on many parameters, such as the earthquake magnitude, location, intensity, proximity to population in the area, frequency content of ground motions in relation to important structures, and others. With a small area and a population of 23 million, Taiwan ranks among the top in population density in the world. Any on-land large and shallow earthquake is likely to be a damaging earthquake. A similar situation applies equally to many earthquake-prone and populous areas in the world.

Many researchers investigated the relationships between seismic losses and the peak ground motion amplitude, such as peak ground-motion acceleration (PGA) and peak groundmotion velocity (PGV) (Tsai et al., 2001; Wu et al., 2002, 2003, 2004). However, for seismic early-warning purposes, we need to identify the areas that are most likely to sustain damage as early as possible before the peak motion occurs.

An earthquake excites both $P$ and $S$ waves. The $S$ wave carries the major destructive energy, and the smalleramplitude $P$ wave precedes the $S$ wave by the time equal to the $70 \%$ of the $P$-wave travel time to the station. The initial portion of the $P$ wave, despite its small and nondestructive amplitude, carries the information of the earthquake size, and a good determination of the earthquake size from the $P$ wave provides information about the strength of shaking being brought by the following $S$ wave. In this study we investigate the possibility of estimating PGA and PGV at a site from the very beginning of the record at the same site as a follow-up of our previous work (Wu and Kanamori, 2005).

\section{Data and Analysis}

Large and shallow earthquakes often cause the most serious damage. We selected 26 events in Taiwan for this study (Table 1). The selection criteria are $M_{\mathrm{w}}>5.0$ and focal depth $<35 \mathrm{~km}$ listed in both the Central Weather Bureau (CWB) and the Harvard catalogs. All the events were well recorded by the Taiwan Strong Motion Instrumentation Program (TSMIP) network. These events occurred from 1993 to 2003 and were widely felt in Taiwan. With about 650 modern digital accelerographs installed at free-field sites (Fig. 1), the TSMIP station signals are digitized at 200 samples per second or higher with 16-bit resolution. Most accelerographs have a dynamic range of $\pm 2 g$.

A total of 208 TSMIP records are used for this study. The vertical-component records of the closest eight stations with an epicentral distance of less than $30 \mathrm{~km}$ are used for quick assessment.

The acceleration signals are integrated to velocity and displacement. We apply a $0.075-\mathrm{Hz}$ high-pass recursive Butterworth filter to remove the low-frequency drift after the last integration. An automatic $P$ picker described by Allen (1978) is used to detect the $P$ arrival from the verticalacceleration records.

We use the peak values of acceleration $(\mathrm{Pa})$, velocity $(\mathrm{Pv})$, and filtered displacement $(\mathrm{Pd})$ determined from the beginning of the $P$ wave. An obvious trade-off exists between the duration of the initial motion and the reliability. For reliable estimation of PGA, PGV, and peak ground-motion dis- 
Table 1

The List of 26 Events Used in This Study

\begin{tabular}{llccrrr}
\hline $\begin{array}{c}\text { Origin time (UT) } \\
\text { (yyyy/mm/dd) }\end{array}$ & $\begin{array}{c}\text { Lat. } \\
(\mathrm{N})\end{array}$ & $\begin{array}{c}\text { Long. } \\
(\mathrm{E})\end{array}$ & $\begin{array}{r}\text { Depth } \\
(\mathrm{km})\end{array}$ & $M_{\mathrm{w}}$ & $\begin{array}{r}\text { No. of Houses } \\
\text { Damaged* }\end{array}$ \\
\hline $1993 / 12 / 15$ & $21: 49: 43.10$ & 23.213 & 120.524 & 12.50 & 5.4 & 0 \\
$1994 / 06 / 05$ & $01: 09: 30.09$ & 24.462 & 121.838 & 5.30 & 6.3 & 25 \\
$1995 / 01 / 10$ & $07: 55: 19.56$ & 23.680 & 121.432 & 3.81 & 5.1 & 0 \\
$1995 / 02 / 23$ & $05: 19: 02.78$ & 24.204 & 121.687 & 21.69 & 6.2 & 0 \\
$1995 / 05 / 27$ & $18: 11: 11.12$ & 23.008 & 121.465 & 19.73 & 5.7 & 0 \\
$1995 / 12 / 18$ & $16: 17: 54.53$ & 24.018 & 121.692 & 22.06 & 5.2 & 0 \\
$1996 / 11 / 26$ & $08: 22: 23.71$ & 24.164 & 121.695 & 26.18 & 5.2 & 0 \\
$1998 / 01 / 18$ & $19: 56: 51.71$ & 22.725 & 121.089 & 3.28 & 5.2 & 0 \\
$1998 / 07 / 17$ & $04: 51: 14.96$ & 23.503 & 120.663 & 2.80 & 5.7 & 183 \\
$1998 / 11 / 17$ & $22: 27: 32.52$ & 22.832 & 120.790 & 16.49 & 5.3 & 0 \\
$1999 / 09 / 20$ & $17: 47: 15.85$ & 23.855 & 120.816 & 8.00 & 7.6 & 106,685 \\
$1999 / 10 / 22$ & $02: 18: 56.90$ & 23.517 & 120.423 & 16.59 & 5.8 & 69 \\
$1999 / 10 / 22$ & $03: 10: 17.46$ & 23.533 & 120.431 & 16.74 & 5.5 & 0 \\
$1999 / 10 / 30$ & $08: 27: 49.50$ & 24.017 & 121.319 & 14.36 & 5.4 & 0 \\
$2000 / 02 / 15$ & $21: 33: 18.15$ & 23.316 & 120.740 & 14.71 & 5.2 & 0 \\
$2000 / 07 / 14$ & $00: 07: 32.46$ & 24.048 & 121.728 & 7.19 & 5.4 & 0 \\
$2000 / 08 / 23$ & $00: 49: 16.58$ & 23.636 & 121.635 & 27.48 & 5.3 & 0 \\
$2000 / 09 / 10$ & $08: 54: 46.53$ & 24.085 & 121.584 & 17.74 & 5.8 & 0 \\
$2001 / 06 / 14$ & $02: 35: 25.78$ & 24.419 & 121.928 & 17.29 & 5.9 & 0 \\
$2001 / 06 / 19$ & $05: 16: 15.46$ & 23.177 & 121.077 & 6.58 & 5.3 & 0 \\
$2001 / 06 / 19$ & $05: 43: 39.17$ & 23.197 & 121.098 & 11.70 & 5.1 & 0 \\
$2002 / 02 / 12$ & $03: 27: 25.00$ & 23.741 & 121.723 & 29.98 & 5.7 & 0 \\
$2002 / 04 / 03$ & $18: 06: 10.79$ & 24.322 & 121.868 & 12.87 & 5.3 & 0 \\
$2002 / 05 / 15$ & $03: 46: 05.91$ & 24.651 & 121.872 & 8.52 & 6.1 & 0 \\
$2003 / 06 / 16$ & $18: 33: 38.85$ & 23.543 & 121.654 & 28.26 & 5.5 & 0 \\
$2003 / 12 / 10$ & $04: 38: 13.52$ & 23.067 & 121.398 & 17.73 & 6.8 & $\dagger$ \\
\hline
\end{tabular}

*Data from Central Weather Bureau (2003).

Damage under investigation.

placement (PGD), the longer the duration the better. However, too long a duration compromises the ability for early warning. Following the analysis of Wu and Kanamori (2005) for Taiwan, we use a duration of $3 \mathrm{sec}$ for estimation of the initial amplitude.

\section{Results}

In general, the ground-motion amplitudes correlate with the amplitude of the initial motions such as $\mathrm{Pa}, \mathrm{Pv}$, and $\mathrm{Pd}$, especially when the averages of the eight stations are taken. However, the correlation is poor if $\mathrm{Pa}$ is used as the amplitude parameter for the initial motion. For a nearby small event, Pa can be large but the PGA and PGV are small. Pa is determined by a very-high-frequency wave with short duration which does not have a high-damage potential. In contrast, $\mathrm{Pv}$ and $\mathrm{Pd}$ contain more long-period energy than $\mathrm{Pa}$ and correlate well with PGA and PGV. In particular, Pd correlates well with the peak amplitude parameters. (The peak amplitudes, PGA, PGV, and PGD are determined from the largest amplitude of the three components.) Figure 2 compares Pd with the high-pass-filtered PGD for all the records. Except for the Chi-Chi earthquake, the filtered PGD values increase with Pd approximately linearly. As indicated by the large filled star symbols in Figure 2, all the damaging events have the filtered PGD larger than $4 \mathrm{~cm}$. Figure 2 demon-

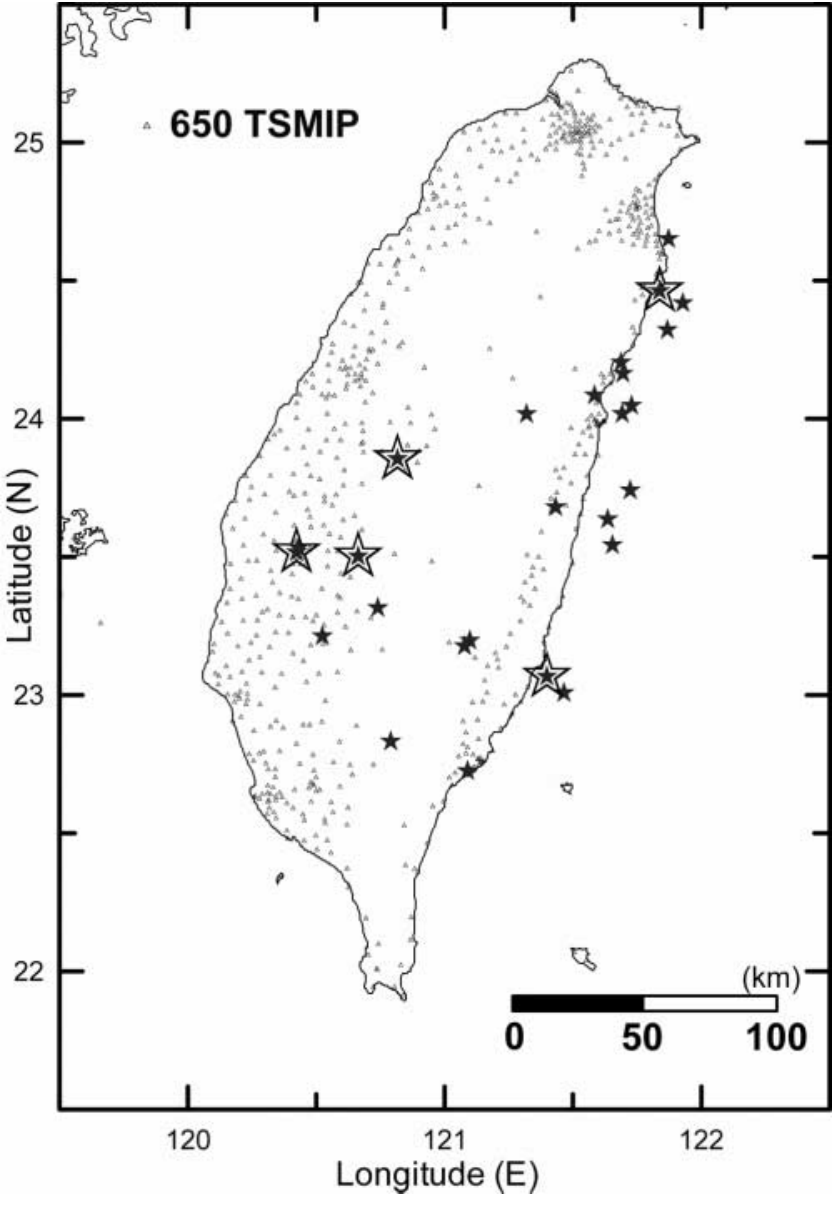

Figure 1. Distribution of stations of the TSMIP and the epicenters of 26 events (stars) used in this study. The larger open stars are the five damaging earthquakes.

strates that if Pd is larger than $0.5 \mathrm{~cm}$, it indicates that the event is damaging.

Figure 3 presents a similar plot showing the relation between PGV and Pd for the same data set. The filled symbols indicate the average for each event. For the average values, we obtain a regression relation

$$
\log (\mathrm{PGV})=0.832 \log (\mathrm{Pd})+1.481,
$$

where PGV is in centimeters per second and Pd is in centimeters.

Wu et al. (2003) obtained the following relation between the Taiwan Intensity $I_{t}$ and PGV.

$$
I_{t}=2.138 \log (\mathrm{PGV})+1.890 .
$$

Combining (1) and (2), we can estimate $I_{t}$ from Pd as

$$
I_{t}=1.779 \log (\mathrm{Pd})+5.056,
$$

where Pd is in centimeters. 


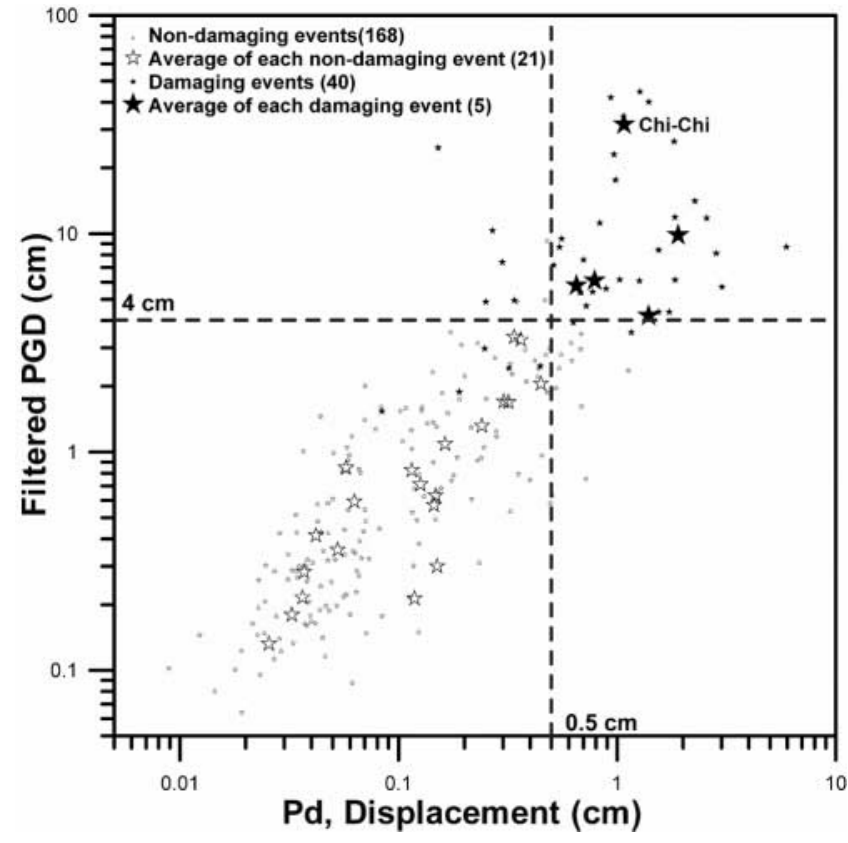

Figure 2. Relationship between peak initial displacement amplitude (Pd) and $0.075 \mathrm{~Hz}$ high-passfiltered peak ground displacement (PGD) for the 26 events.

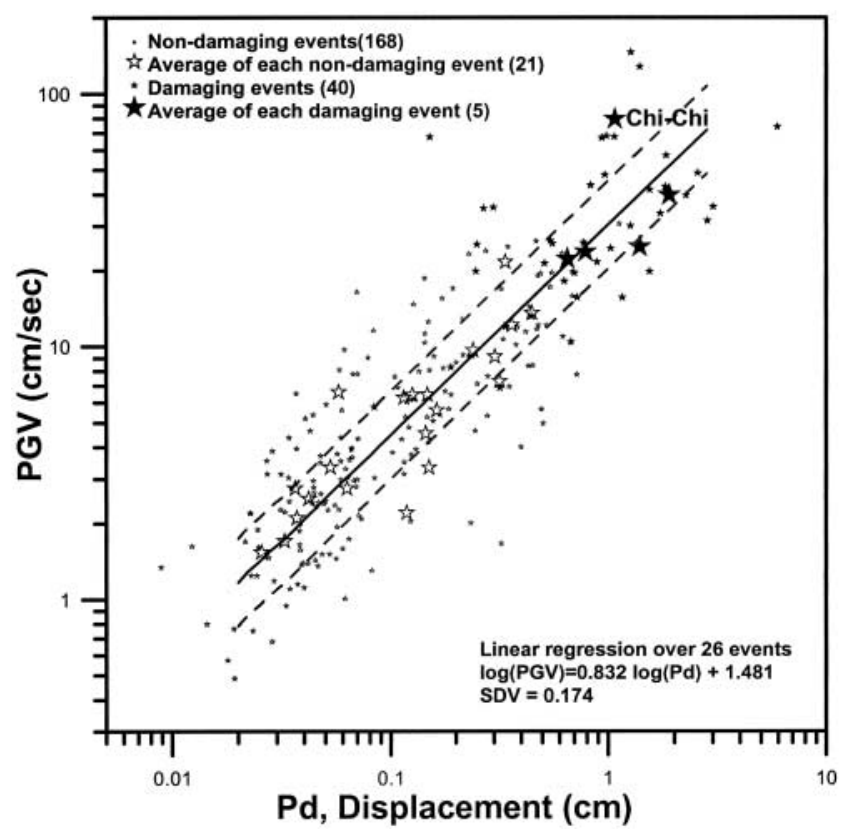

Figure 3. Relationship between peak initial displacement amplitude (Pd) measurements and peak ground velocity (PGV) for the 26 events. Solid line shows the least-squares fit and two dashed lines show the range of one standard deviation.
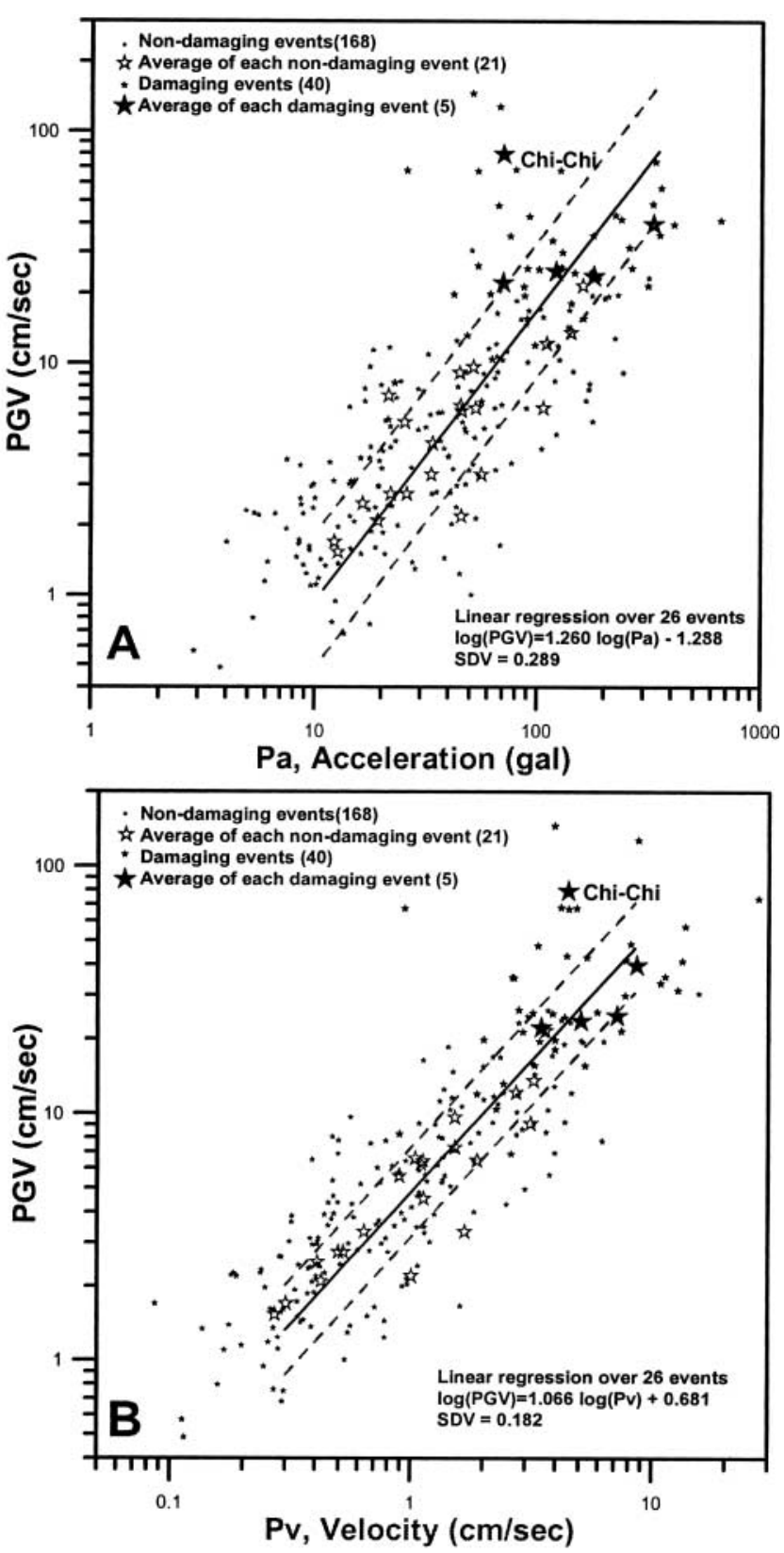

Figure 4. (A) Relationship between peak initial acceleration amplitude $(\mathrm{Pa})$ measurements and peak ground velocity (PGV) for the 26 events. (B) Peak initial velocity amplitude $(\mathrm{Pv})$ measurements and PGV for the 26 events. Solid line shows the leastsquares fit and two dashed lines show the range of one standard deviation.

Figure 4 presents two similar plots showing the relations between $\mathrm{Pa}, \mathrm{Pv}$, and PGV for the same data set. As mentioned previously, $\mathrm{Pv}$ and $\mathrm{Pd}$ contain more long-period energy than $\mathrm{Pa}$ and correlate better with PGV.

Wu and Kanamori (2005) determined a period parameter $\tau_{c}$ for the same data set used here by using a method modified from Nakamura (1988). The parameter $\tau_{c}$ is determined from the ratio of integrals of the velocity squared to 


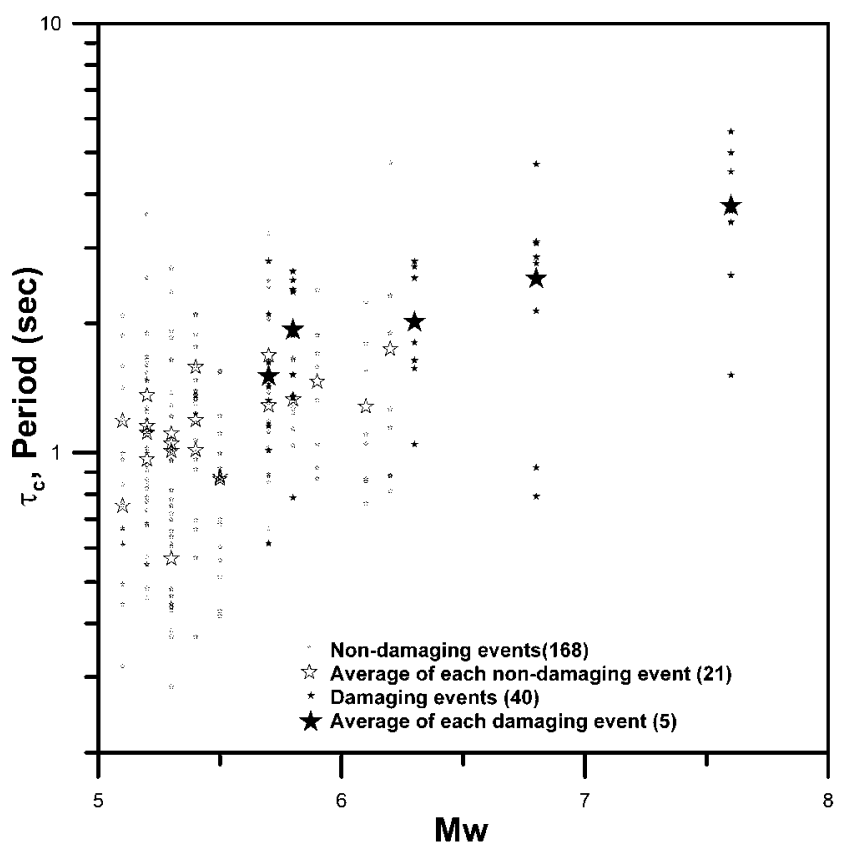

Figure 5. Relationship between period parameter $\left(\tau_{c}\right)$ for the 26 events and moment magnitude $\left(M_{\mathrm{w}}\right)$.

that of the displacement squared and, in principle, is independent of the distance at least to the first order. Figure 5 shows $\tau_{c}$ for all the events (open symbols) and the average $\tau_{c}$ (filled symbols) as a function of $M_{\mathrm{w}}$. In general, the $\tau_{c}$ values increase with $M_{\mathrm{w}}$ and are useful for magnitude determinations (Kanamori, 2005; Wu and Kanamori, 2005). Damaging events are indicated by star symbols.

We combine these two parameters as a single indicator to improve reliability. Figure 6 shows $\tau_{c}^{*} \mathrm{Pd}$ values for all the events (open symbols) and their average (filled symbols) as a function of $M_{\mathrm{w}}$. Damaging events are indicated by star symbols. The product $\tau_{c}{ }^{*} \mathrm{Pd}$ gives a clearer indicator for discriminating damaging events from nondamaging events. The value $\tau_{c} * \mathrm{Pd}=1.0 \mathrm{sec}-\mathrm{cm}$ is a good threshold for identifying damaging earthquakes.

Note that because Pd depends not only on the magnitude but also on the distance, we do not generally expect a unique relationship between the amplitudes and $M_{\mathrm{w}}$. For the Taiwan data set we used here, the average epicenter-station distance is approximately $20 \mathrm{~km}$ for all the events. Thus, Figure 6 with the threshold of $\tau_{c}{ }^{*} \mathrm{Pd}=1.0 \mathrm{sec}-\mathrm{cm}$ should be used only for the station-epicenter geometry of Taiwan.

In other areas where the station distribution is not as dense and uniform as in Taiwan, we may use $\tau_{c}$ and $\mathrm{Pd}$ independently. If both $\tau_{c}$ and $\mathrm{Pd}$ are measured at a station or at a group of stations, then four combinations are possible: (1) $\mathrm{Pd}>0.5 \mathrm{~cm}$ and $\tau_{c}>1.0 \mathrm{sec}$; (2) $\mathrm{Pd}<0.5 \mathrm{~cm}$ and $\tau_{c}>1.0 \mathrm{sec}$; (3) $\mathrm{Pd}<0.5 \mathrm{~cm}$ and $\tau_{c}<1.0 \mathrm{sec}$; and (4) $\mathrm{Pd}>0.5 \mathrm{~cm}$ and $\tau_{c},<1.0 \mathrm{sec}$. Corresponding warnings are: (1) the event is most likely damaging in the station area

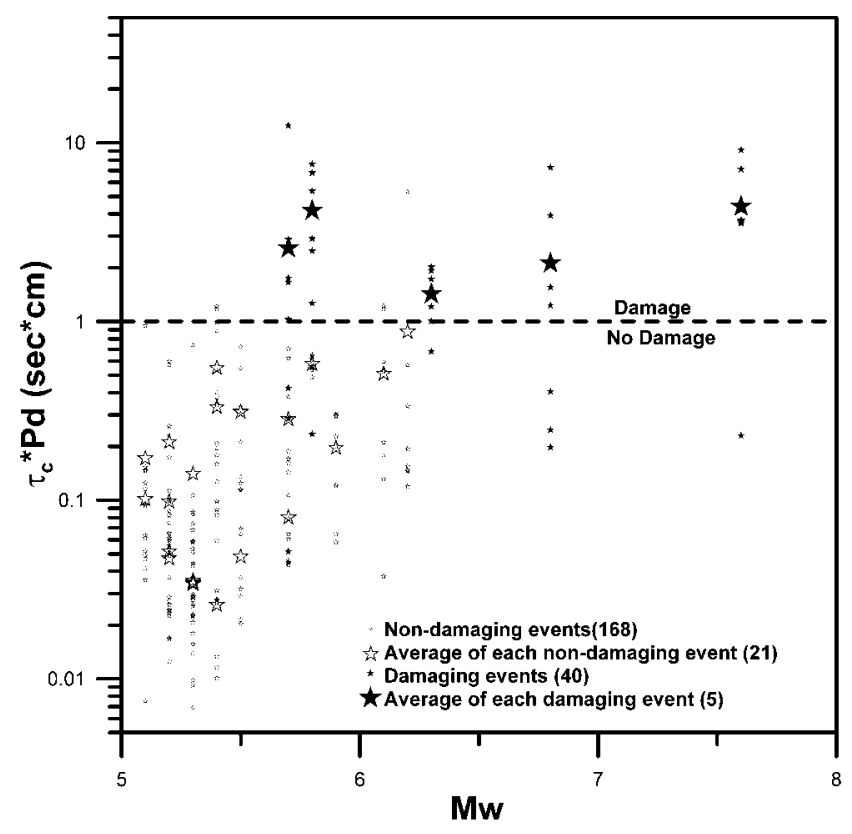

Figure 6. Relationship between $\tau_{c} \times \mathrm{Pd}$ and $M_{\mathrm{w}}$ for the 26 events, where $\tau_{c}$ is the period parameter and $\mathrm{Pd}$ is the peak initial displacement amplitude.

as well as a larger area; (2) the event is not damaging in the station area, but it can be damaging in other areas; (3) the event is not damaging; (4) the event is damaging only in the limited area around the station.

\section{Discussions and Conclusions}

Large earthquakes in populated areas are potentially damaging. The high population density of Taiwan and the dense distribution of the TSMIP stations in the populated areas allow us to investigate the correlation between the damage and ground-motion parameters and to develop a method for reliable and early assessment of damaging earthquakes.

The method described here has a wide application. These days, almost every populated area has internet connection, and modern strong-motion instruments are equipped with an internet-networking function; all the processes discussed in this study can be carried out in automatic and real-time operation mode. The software to compute $\tau_{c}$ and Pd can be easily installed on site. Once a $P$ arrival produces a trigger, only the $P$ arrival, $\tau_{c}$, and Pd values (instead of the entire waveforms) are sent to the control center. By using the averaged values from the first eight stations as indicators, a quick identification of a damaging earthquake can be achieved within $8 \mathrm{sec}$ of the earthquake origin time. Also, $P$ arrivals, $\tau_{c}$, and Pd measurements can jointly be used to determine the hypocenter, magnitude, and the sourceregion intensity, respectively. 


\section{Acknowledgments}

We thank Prof. Ta-liang Teng for greatly improving this article and providing many thought-provoking comments. We also thank Prof. Friedemann Wenzel for reviewing this article and providing many valuable comments. This research was supported by the Central Weather Bureau and Grants NSC 92-2119-M-002-026 and NSC 93-2119-M-002-030 from the National Science Council of the Republic of China.

\section{References}

Allen, R. V. (1978). Automatic earthquake recognition and timing from single traces, Bull. Seism. Soc. Am. 68, 1521-1532.

Allen, R. M., and H. Kanamori (2003). The potential for earthquake early warning in Southern California, Science 300, 685-848.

Central Weather Bureau (2003). One Hundred Questions about Earthquake Central Weather Bureau, Taipei, Taiwan, 66 pp. (in Chinese).

Kanamori, H. (2005). Real-time seismology and earthquake damage mitigation, Annu. Rev. Earth Planet. Sci. 33, 5.1-5.20.

Kanamori, H., E. Hauksson, and T. Heaton (1997). Real-time seismology and earthquake hazard mitigation, Nature 390, 461-464.

Nakamura, Y. (1988). On the urgent earthquake detection and alarm system (UrEDAS), in Proceedings of 9th World Conference on Earthquake Engineering, Tokyo-Kyoto, Japan.

Teng, T. L., Y. M. Wu, T. C. Shin, Y. B. Tsai, and W. H. K. Lee (1997). One minute after: strong-motion map, effective epicenter, and effective magnitude, Bull. Seism. Soc. Am. 87, 1209-1219.

Tsai, Y. B., T. M. Yu, H. L. Chao, and C. P. Lee (2001). Spatial distribution and age dependence of human-fatality rates from the Chi-Chi, Tai- wan, earthquake of 21 September 1999, Bull. Seism. Soc. Am. 91, 1298-1309.

Wu, Y. M., and H. Kanamori (2005). Experiment on an onsite early warning method for the Taiwan early warning system, Bull. Seism. Soc. Am. 95, no. 1, 347-353.

Wu, Y. M., and T. L. Teng (2002). A virtual sub-network approach to earthquake early warning, Bull. Seism. Soc. Am. 92, 2008-2018.

Wu, Y. M., N. C. Hsiao, and T. L. Teng (2004). Relationships between strong ground motion peak values and seismic losses during the 1999 Chi-Chi, Taiwan earthquake, Nat. Hazards 32, 357-373.

Wu, Y. M., N. C. Hsiao, T. L. Teng, and T. C. Shin (2002). Near real-time seismic damage assessment of the rapid reporting systems, TAO 13, 313-324.

Wu, Y. M., T. L. Teng, T. C. Shin, and N. C. Hsiao (2003). Relationship between peak ground acceleration, peak ground velocity, and intensity in Taiwan, Bull. Seism. Soc. Am. 93, 386-396.

Department of Geosciences

National Taiwan University

Taipei 106, Taiwan

(Y.-M.W.)

Seismological Laboratory

California Institute of Technology

Pasadena, California 91125

(H.K.)

Manuscript received 28 September 2004. 